\title{
Economic analysis of safety risks in construction
}

\author{
F. M. Almeida Santos ${ }^{1}$, T. Bourbon ${ }^{1} \&$ A. Soeiro ${ }^{2}$ \\ ${ }^{I}$ Tabique Lda, Portugal \\ ${ }^{2}$ Universidade do Porto, Portugal
}

\begin{abstract}
The objective of this study revolves around the analysis of the safety risks involved with one construction project, and the respective economic effects of risk prevention and safety management. As a result of the co-ordination of systems, and harmonising of work between the Project Leader, Safety Co-ordinator and Contractor, an adequate strategy was developed for the safety of the project Escola de Ciências da Saúde da Universidade do Minho. This project is situated in the centre of the city Braga. The area is destined to become a High Medical School. The construction area covers around 30,000 $\mathrm{m}^{2}$. The management policy on Prevention, Hygiene and Safety is ensured by the following bodies with respective collaborations: General Safety Committee/ Prevention and Safety Officer; Co-ordination of on-site safety/General Safety Committee, from the point of view of Project Leader / Safety Co-ordinator. The risk evaluation is carried out in simulated form, and task by task, introduced into the work programme. This gives a history of risk evaluation over the course of the project. The simulation allows peaks of risk to be identified, which will then lead to additional proposals of prevention measures. These prevention measures will serve to reduce risk and consequently lead to a curve on the risk chart. They consist not only of on-site measures, but also of the integrated implementation of working safety policies. The implementation of prevention systems and working safety policies has its own cost, but what we intend to prove, by attributing costs to risks, is that safety has lower costs than a lack of safety.
\end{abstract}

Keywords: construction, safety, risk analysis, risk management, accidents, risk prevention, prevention costs, safety plans. 


\section{Introduction}

The Safety and Health Coordination Staff of the Escola de Ciências da Saúde da Universidade do Minho Project, Braga, Portugal, in collaboration with the Civil Engineering Department of Minho University, has decided to make an economic study of risks, through its study during the work. This programme will be based on the detailed working programme that has been approved for execution.

The project programme required the foundations to start on March 2005, and project completion to end by October 2006, approximately one year and a half, in duration [1]. To each of the working programme activity it is associated a risk evaluation dossier by the Safety Coordination, containing not only risks, but also preventive measures.

The evaluation of risks and choice between a preventive or non-preventive attitude leads to two different situations: a good safety performance or the inexistence of safety during the work. For each of these extremes in terms of safety prevention the risk is calculated for each task with a combination of probability of occurrence and the associated damage caused. The accumulated values of these risks represent the range of expected risk that is expected connected with the tasks planned for each period of analysis. At the end there are two final risk histograms representing the extreme situations.

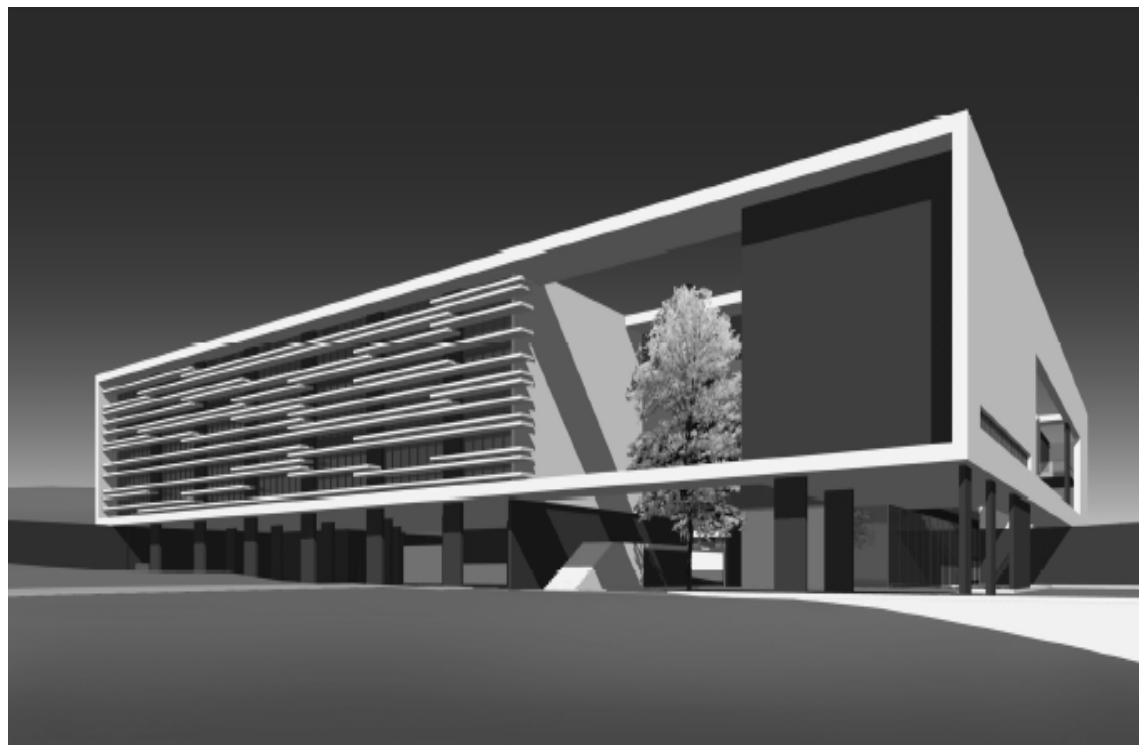

Figure 1: Panoramic view of Escola de Ciências da Saúde da Universidade do Minho. 


\section{Experimental work}

With the detailed execution plan of Escola de Ciências da Saúde da Universidade do Minho Work as a basis for safety plan, it was been done a study of total risks associated to the different activities [2]. Two simulations have been made taking into consideration that one concerned situation with the maximum risk evaluation, stressed by the inexistence of preventive measures on the works, and that the other, that satisfied all preventive measures. The latter was considered without eliminating all risks, since accidents can always occur despite safety measures taken.

The risk associated to the activities of the working plan, that had more than 1000 activities, is analysed in each one. This analysis was done after considering the information included in the Safety and Health Plan that was being implemented on site [3]. The Safety and Health Plan contains Inspection and Prevention Procedures adaptable to the activities, related to the risks of each activity, as well as the preventive measures that should be implemented on site, in order to minimise the correspondent risks.

Therefore, it has been elaborated an inspection and prevention procedures table for each activity. To optimise the use of that data, the safety procedures became part of the construction plan activities [4]. For each Inspection and Prevention Procedure, i.e., for each activity, there are various risks associated. In the construction site referred in this study, 82 types of risk were detected. These risks have varying probabilities of occurrence. According to the computer program used, these risks are included in the resources of the different construction activities.

In order to evaluate risks, an evaluation table was developed, that considers the severity and the probability of occurrence. The risk scale ranges from 1 to 5 , taking into account that there is no null value risk. Taking into consideration the lack of prevention at the work, a maximum value for each risk has been defined, as in some cases it reached 5, for instance height falls. Risk 1 was defined considering the full use of prevention, whichever the circumstance, as this is, as previously referred, the minimum risk value assumed.

After considering all those elements, the experimental phase of the study was implemented. The analysis consisted in inserting in the "Primavera Project Planner", a project management computer program, all related activities. These were those of the approved construction plan and the risks values were considered as an activity resource data.

After that analysis, the simulation values of risk to both extreme situations were calculated. One corresponds to total inexistence of prevention measures and the other to complete prevention measures [5]. The study of both risk situations is done using the histogram of the project plan related as its basis.

\section{Results of analysis}

According to the data inserted in the program, results are simulated for both situations. In the first situation, where risk analysis is maximised, taking into consideration the fact that there is no prevention, there is a total result of 356663 
risk points, resulting from the addition of all risks related to the activities. In the second situation, assuming that there is full prevention of risks at all levels, the total of risk points totals 92354. A simple conclusion of these two numbers is that when prevention is not implemented the total risk is about 4 times greater than when prevention is fully implemented.

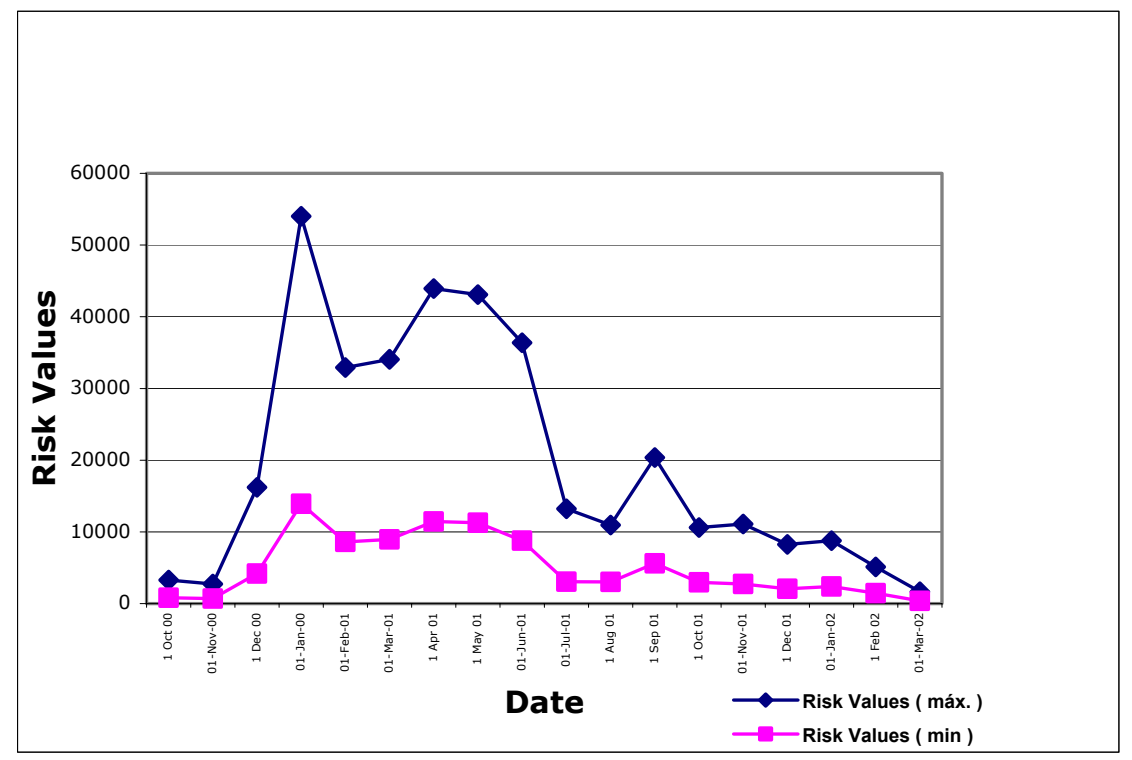

Figure 2: $\quad$ Evolution of risk values.

\section{Discussion of results}

Taking into consideration that 3.86 is the maximum average reference point, during the construction period, it is quickly noticed that in different phases, the difference of risk occurrence highly surpasses these values. Therefore, apart from normal prevention situations, it is extremely important to act in the periods when these peak risks occur. A parallel analysis can also be done to evaluate the risks and costs associated. This can show the values that represent the costs to create a certain level of safety.

Taking into consideration recent studies that show that safety costs for similar projects in Portugal are about $2 \%$ of the construction cost, it is possible to say that this percentage may correspond to cost associated with the maximisation of risk prevention measures implemented in the work. This study shows that risk maximisation without prevention is about 3.86 times larger, which also means that costs of lack of safety can reach $7.72 \%$ of total construction costs, i.e., $5.72 \%$ more than the costs of implementing safety measures.

Application of these values to the Escola de Ciências da Saúde da Universidade do Minho, with an estimated value of 15 millions of Euros, results in the following costs: 
a) Costs of implementation of prevention measures

$(2,0 \%) \sim 0.30$ millions Euros

b) Potential costs of non-safety

$(7,7 \%) \sim 1.16$ millions Euros

c) Potential risk of added costs due to the non-existence of prevention $(5,7 \%) \sim 0,86$ million Euros

It is important to remember that the cost of non-safety is composed by quantifiable values (fines, employees' salaries, lawyers, spoiled material, etc) and by unquantifiable values (work interruption, reduced of productivity, boarder of directors' time marginalised, company image, prestige, etc). In this study the latter ones are no included in this study.

\section{Conclusion}

This study clearly indicates that it is beneficial to invest in prevention. Apart from the need to minimise task risks, through the inclusion of safety measures in the Inspection and Prevention Procedures for tasks, there are other measures which can be implemented to realise even more benefits like coordination meetings with all contributors, safety working commission meetings, training, counselling, and informing of all workers and managers, discussing of the Safety and Health Plan with all participants from all working sectors, throughout the project and planning all activities in order to assure the implementation of safety measures in future work.

All these measures are solutions that approximate safety costs from values practised, by those that care about prevention, and risk minimisation. The risk management approach can easily be implemented to address the most dangerous situations that are expected to occur. That can contribute to a more efficient safety management and to decrease the costs of prevention. It is, therefore, logical to state the aphorism "Decreasing risks means decreasing total construction costs".

\section{References}

[1] Alves Dias, J., Plano de Segurança e Saúde, IDICT, Portugal, 1997.

[2] Reis C., Análise Económica de Segurança na Construção, Universidade do Porto, Mestrado em Construção de Edifícios, Portugal, 1998.

[3] Santos J. M, Rodrigues M. F., Baptista M. A., Santos Reis S., Maduro Roxo M., Coordenação de Segurança na Construção, IDICT, Portugal, 1999.

[4] Soeiro A., Almeida Santos F. M., Reis C., Economic Overview of Construction Safety, Singh A., Hinze J., Coble R.J., ed., USA, 1999.

[5] Alves Dias J., Safety and Health on Construction Sites, CIB W099, Netherlands, 2000. 